\title{
Single impact cartilage trauma and TNF- $\alpha$ : Interactive effects do not increase early cell death and indicate the need for bi-/multidirectional therapeutic approaches
}

\author{
CATHRIN HOGREFE $^{1 *}$, HELGA JOOS $^{1 *}$, VENNILA MAHESWARAN $^{1}$, \\ LUTZ DÜRSELEN $^{2}$, ANITA IGNATIUS ${ }^{2}$ and ROLF E. BRENNER ${ }^{1}$ \\ ${ }^{1}$ Division for Biochemistry of Joint and Connective Tissue Diseases, Department of Orthopedics, \\ ${ }^{2}$ Institute of Orthopedic Research and Biomechanics, University of Ulm, Ulm, Germany
}

Received May 24, 2012; Accepted July 30, 2012

DOI: $10.3892 /$ ijmm.2012.1112

\begin{abstract}
Blunt trauma of articular cartilage, often resulting from accidents or sports injuries, is associated with local inflammatory reactions and represents a major risk factor for development of post-traumatic osteoarthritis. TNF- $\alpha$ is increased in synovial fluid early after trauma, potentiates injuryinduced proteoglycan degradation and may act proapoptotic under permissive conditions. We asked whether TNF- $\alpha$ also influences chondrocyte death, gene expression of catabolic and anabolic markers and the release of proinflammatory mediators in the early post-traumatic phase. Interactive effects of a defined single impact trauma (0.59 J) and TNF- $\alpha$ (100 ng/ $\mathrm{ml}$ ) on human early-stage osteoarthritic cartilage were investigated in vitro over $24 \mathrm{~h}$. Exposure of traumatized cartilage to TNF- $\alpha$ did not increase chondrocyte death. IL-6-synthesis was augmented by trauma, TNF- $\alpha$ and combined treatment. The impact increased the release of PGE2 and PGD2 in the presence and absence of TNF- $\alpha$ to a similar extent while TNF- $\alpha$ alone showed no effect. In contrast, NOS2A-expression and nitric oxide (NO)-release were not affected by trauma but significantly increased by TNF- $\alpha$. Expression of OPG and RANKL was not affected by TNF- $\alpha$ but modulated by trauma. TNF- $\alpha$ with and without trauma significantly induced MMP1 gene expression. These results indicate that TNF- $\alpha$ does not potentiate early cell death in early-stage osteoarthritic cartilage after blunt injury. However, trauma and TNF- $\alpha$ showed independent and interactive effects concerning prostaglandin and NO release. TNF- $\alpha$ probably contributes to cartilage degradation after trauma by an
\end{abstract}

Correspondence to: Dr Rolf E. Brenner, Division for Biochemistry of Joint and Connective Tissue Diseases, Department of Orthopedics, University of Ulm, Oberer Eselsberg 45, 89081 Ulm, Germany

E-mail: rolf.brenner@uni-ulm.de

*Contributed equally

Key words: cartilage, trauma, TNF- $\alpha$, cell death, prostaglandins, nitric oxide early induction of MMP1 gene expression. Our study confirms that an anti-TNF- $\alpha$ therapy may have inhibitory effects on catabolic and, partly, on inflammatory processes after a single impact trauma. As TNF- $\alpha$ does not contribute to the loss of chondrocytes in the initial post-traumatic phase, a combination with pharmaco-therapeutic strategies reducing early cell death could be reasonable.

\section{Introduction}

Traumatic joint damage is a major risk factor for development and/or progression of osteoarthritis (OA) (1). Knee injuries often result from traffic accidents and count for $40 \%$ of sports injuries (2-4). The high prevalence of post-traumatic arthritis creates the urgent need for pharmacological interventions, starting in the early phase after injury in which the destructive processes are induced $(1,5)$. Therefore, a detailed knowledge of the underlying pathogenetic mechanisms is crucial but only partly available. The excessive mechanical loading of the articular cartilage results in chondrocyte death that can be attributed to mechanical necrosis (6) and apoptotic processes (7). In addition, mechanical disruption of the extracellular matrix leads to an early loss of glycosaminoglycans (8). Cartilage defects in knee injuries are commonly associated with other pathological conditions of the joint such as anterior cruciate ligament (ACL) ruptures and meniscal injuries (9), leading to an increase of proinflammatory cytokines in the synovial fluid (10). Beside IL-1 $\beta$ and IL-6, which are elevated during the first 3 to 6 days, the level of TNF- $\alpha$ is significantly increased over a period of 3 weeks after ACL ligament injury of the knee with a peak concentration in the first $24 \mathrm{~h}$ (11).

Proinflammatory cytokines are known to drive the overall inflammatory process by inducing other cytokines, chemokines and proinflammatory mediators like prostaglandins and NO $(12,13)$. These cytokines enhance cartilage degradation via an activation of catabolic and a decrease of anabolic processes. In particular, degenerative enzymes like matrix metalloproteinases (MMP) 1, 3 and 13 as well as aggrecanases (e.g. ADAMTS 4/5) are induced by TNF- $\alpha$ and/or IL-1 $\beta$ (14-16). In vitro studies with human and bovine cartilage revealed that TNF- $\alpha$ and IL- $1 \alpha$ potentiate the effect of cartilage impact, leading to a synergistic 
loss of proteoglycans and to a reduction of their biosynthesis $(17,18)$. In contrast, IL-1 $\beta$ co-stimulation had no additive effects on cell death in traumatized cartilage during the first $24 \mathrm{~h}$ but prostaglandin (PGE2 and PGD2) and NO synthesis pathways were both affected by trauma and/or IL-1 $\beta$ (19). In an apoptosis model of chondrocytes sensitized by actinomycin D, TNF- $\alpha$ but not IL-1 $\beta$ was described to enhance apoptosis indicating differential regulations by these cytokines $(20,21)$. So far, no studies exist on interactions of TNF- $\alpha$ and a single impact cartilage trauma with respect to cell death, prostaglandin or NO metabolism.

Besides well-known effects on cartilage degeneration and inflammation in arthritic diseases like induction of MMPs, aggrecanases, inducible nitric oxide synthase and cyclooxygenase $(22,23), \mathrm{TNF}-\alpha$ is also involved in the regulation of bone remodeling by stimulation of receptor activator of nuclear factor $(\mathrm{NF}-\mathrm{\kappa B})$ ligand (RANKL) expression in osteoblasts. Binding of RANKL to its receptor RANK on osteoclasts increases bone resorption by promoting their differentiation and activation (24). RANKL and its decoy receptor osteoprotegerin (OPG) are also expressed in human chondrocytes and may play a role in osteoarthritis, where OPG production is increased (25). They may alter the remodeling process of subchondral bone which becomes sclerotic during development of post-traumatic OA.

Overall, TNF- $\alpha$ could have significant influence in the early phase after cartilage trauma. A deeper knowledge of its contribution to induction or progression of post-traumatic OA could be directive for new therapeutic approaches. Therefore, the primary aims of the present study were to elucidate, whether TNF- $\alpha$ potentiates chondrocyte death, alters the release of proinflammatory mediators (PGE2, PGD2, NO and IL-6) and modulates OPG/RANKL expression in human cartilage in the initial phase after a defined single impact trauma. We further asked if these treatments have early effects on gene expression of catabolic enzymes and cartilage matrix components.

\section{Materials and methods}

In order to investigate whether TNF- $\alpha$ could alter the described trauma-induced processes under in vitro circumstances (Fig. 1) we used human cartilage, obtained from donors undergoing total knee joint replacement due to osteoarthritis with informed consent of the patients according to the terms of the Ethics Committee of the University of Ulm. Overall, tissue samples from 16 patients were included in the study. The mean age of the donors was $68 \pm 8.1$ years (range 50-78 years). Only tissue from less affected femoral condyles was used that had a macroscopically smooth surface and no severe osteoarthritic changes.

Cartilage explants. Full-thickness cartilage explants, $6 \mathrm{~mm}$ in diameter, were harvested by punching the cartilage with a biopsy punch and separating the cartilage from the underlying subchondral bone with a scalpel. Each explant was weighed and cultivated in a medium consisting of 1:1 DMEM/Hams F12 supplemented with $10 \%$ fetal bovine serum, $0.5 \%$ penicillin/streptomycin (PAA Laboratories, Pasching, Austria), $0.5 \%$ L-glutamine and $10 \mu \mathrm{g} / \mathrm{ml}$ 2-phospho-L-ascorbic acid trisodium salt (Sigma-Aldrich, Fluka, Seelze, Germany) for $24 \mathrm{~h}$ in an incubator $\left(37^{\circ} \mathrm{C}, 21 \% \mathrm{O}_{2}, 5 \% \mathrm{CO}_{2}\right)$. Afterwards, the explants were cultivated for $24 \mathrm{~h}$ in serum-free medium consisting of DMEM supplemented with $1 \%$ sodium pyruvate, $0.5 \%$ L-glutamine, $1 \%$ non-essential amino acids, $0.5 \%$ penicillin/streptomycin and $0.1 \%$ serum effective substitute (SES-1 solution A). SES-1 solution B was freshly added to the medium in each case. All chemicals were purchased from Biochrom (Berlin, Germany) unless specified otherwise.

Impact loading and TNF- $\alpha$ treatment. Blunt injury of the cartilage explants was achieved with the help of a specially designed drop-tower. It imparts loads to an indenter, a flat-faced steel rod of $15 \mathrm{~mm}$ in diameter, resting on the explant surface as described previously (19). The impact energy was applied by dropping a $600 \mathrm{~g}$ mass from a height of $10 \mathrm{~cm}$ on the indenter, which resulted in an impact energy of $0.59 \mathrm{~J}$. Unloaded explants served as controls. In addition to the impact loading, some of the cartilage explants were treated with TNF- $\alpha(100 \mathrm{ng} / \mathrm{ml})$ (PeproTech, Hamburg, Germany). Twenty-four hours after these treatments the cartilage explants and the culture media were harvested.

mRNA isolation and cDNA synthesis. For total RNA isolation the cartilage explants were frozen in liquid $\mathrm{N}_{2}$. After pulverization with a microdismembrator (Sartorius BBI Systems, Melsungen, Germany), RNA was isolated using the Lipid Tissue Mini kit (Qiagen, Hilden, Germany). RNA was reverse transcribed with the Omniscript RT kit (Qiagen) and used for quantitative real-time PCR-analysis (StepOnePlus ${ }^{\mathrm{TM}}$ Real-Time PCR System, Applied Biosystems, Darmstadt, Germany).

Real-time polymerase chain reaction (PCR). Relative gene expression analysis $\left(2^{-\Delta \Delta \mathrm{Ct}}\right.$ method) using the Platinum ${ }^{\circledR} \mathrm{SYBR}^{\circledR}$ qPCR SuperMix UDG (Invitrogen, Darmstadt, Germany) was used for NOS2A, 5'-ATTCACTCAGCTGTGCATCG-3' (forward) and 5'-TCAGGTGGGATTTCGAAGAG-3' (reverse); for COX2, 5'-CCCTTGGGTGTCAAAGGTAA-3' (forward) and 5'-GGCA AAGAATGCAAACATCA-3' (reverse); for PTGES, 5'-CCCCC AGTATTGCAGGAG-3' (forward) and 5'-GGAAGACCAG GAAGTGCATC-3' (reverse); for MMP1, 5'-TTCGGGGA GAAGTGATGTTC-3' (forward) and 5'-ATCTCTGTCGGCAA ATTCGT-3' (reverse); for COL2A1, 5'-AATGGTGGCTTCC ATTTCAG-3' (forward) and 5'-CTGCTTCGTCCAGATAGG CAA (reverse). TaqMan ${ }^{\circledR}$ Gene Expression Master Mix (Applied Biosystems) was used for TaqMan ${ }^{\circledR}$ Gene Expression Assay (Applied Biosystems) Hs00168748_m1 (PTGDS), Hs00968305_ m1 (MMP3), Hs00192708_m1 (ADAMTS4), Hs00199841_m1 (ADAMTS5) and Hs00153936_m1 (ACAN). Power SYBR ${ }^{\circledR}$ Green PCR Master Mix (Applied Biosystems) was used for $18 \mathrm{Sr}$ RNA, 5'-CGC AGCTAGGAATAATGGAATAGG-3' (forward) and 5'-CAT GGCCTCAGTTCCGAAA-3' (reverse), which served as endogenous control. mRNA-expression was determined by real-time PCR after $24 \mathrm{~h}$, expression levels were normalized to 18Sr RNA.

ELISAs and NO assay. Absolute concentrations of nitrite, a stable end-product of the NO metabolism, were determined in the media of the tissue culture using the Griess assay (Griess Reagent System, Promega, Mannheim, Germany) according to the manufacturer's instructions. PGE2 production was measured in the media by PGE2 ELISA Correlate EIA ${ }^{\mathrm{TM}}$ kit (Biotrend, Assay Designs, Cologne, Germany), PGD2 production was measured 


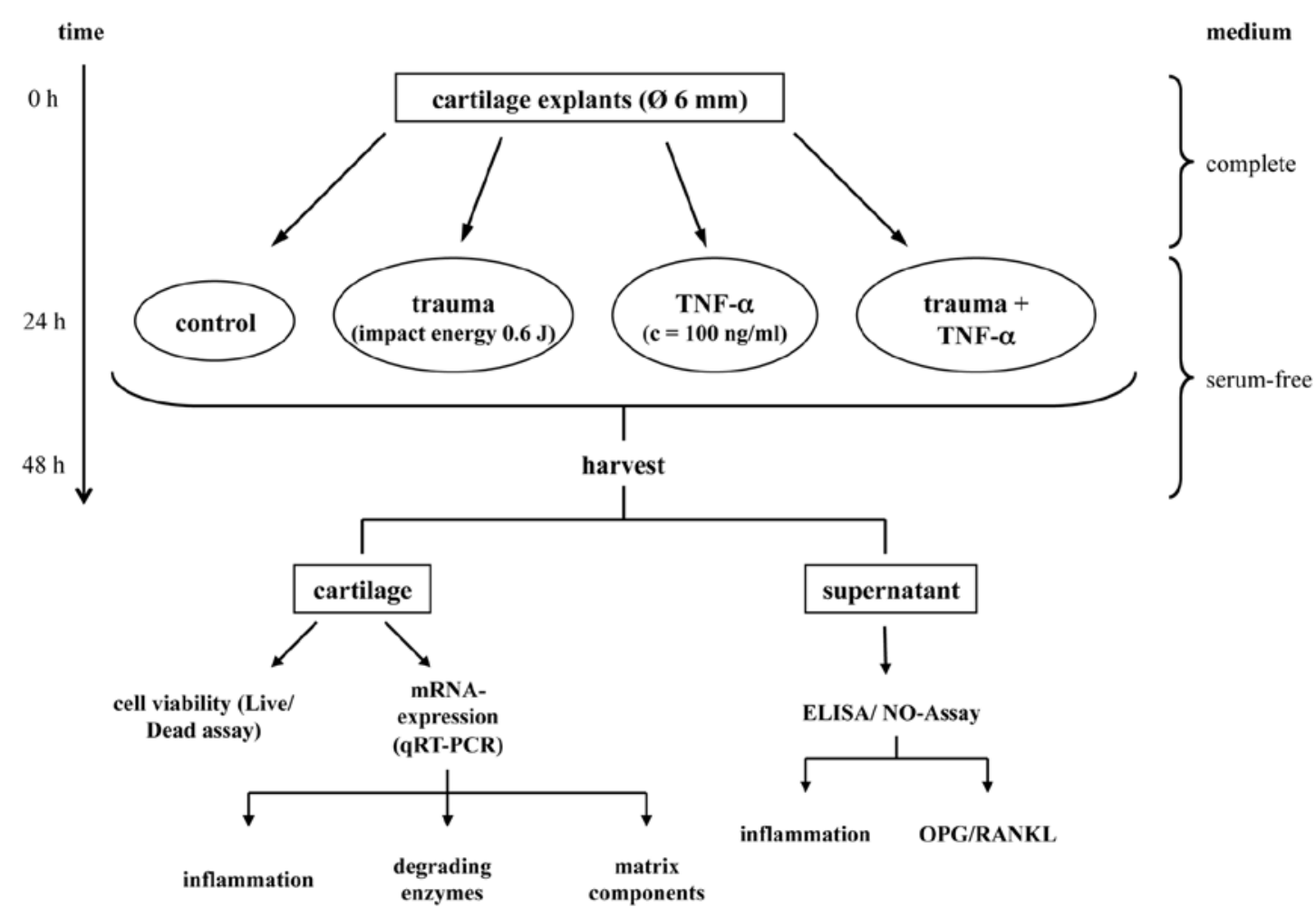

Figure 1. Experimental design of this study.

by Prostaglandin D2 EIA kit (Cayman, Biomol, Hamburg, Germany) and IL-6, IL-1 $\beta$ and TNF- $\alpha$ production was measured by Human IL-6 Quantikine ELISA kit, Human IL-1 $\beta /$ IL-1F2 Quantikine ELISA kit and Human TNF- $\alpha$ Quantikine ELISA kit, respectively (all R\&D Systems, Wiesbaden, Germany), according to the manufacturer's instructions. OPG production was measured by Human Osteoprotegerin/TNFRSF11B DuoSet (R\&D Systems) and RANKL production was measured by ampli-sRANKL ELISA (Biomedica, Vienna, Austria).

Live/dead cell cytotoxity assay. A Live/Dead ${ }^{\circledR}$ Viability/ Cytotoxity assay (Molecular Probes, Invitrogen, Darmstadt, Germany) was performed to determine the percentage of viable cells, which was carried out by staining the chondrocytes of an unfixed tissue section ( $0.5 \mathrm{~mm}$ thickness) with $1 \mu \mathrm{M}$ calcein AM and $2 \mu \mathrm{M}$ ethidium homodimer-1 for $30 \mathrm{~min}$. After washing in PBS, the tissue sections were microscopically analyzed with the help of a z-stack module (software AxioVision, Carl Zeiss, Jena, Germany). A quadruplicate analysis of the basal percentage of living cells showed a standard deviation of $2.9 \%$ and documented good reliability.

Statistical analysis. For standardization of the gene expression levels determined by real-time PCR-analysis, mRNA-expression was normalized to $18 \mathrm{Sr}$ RNA-expression. Differential regulation was determined by calculating the treatment-control ratios of gene expression. The data are presented as box plots, where each box represents the interquartile range. The line inside the box displays the median. The whiskers show the minimum and maximum values. The dependent variables (cell viability, relative gene expression levels and mediator release) were analyzed by one-way ANOVA with Bonferroni's post test for selected pairs of columns using GraphPad Prism version 5.0 for Mac OS X, GraphPad Software, San Diego CA, USA, to evaluate significant differences between different treatment groups. The groups treated with trauma, TNF- $\alpha$ or trauma plus TNF- $\alpha$ (independent variables) were compared to the control group. $\mathrm{p}<0.05$ was regarded as significant and $\mathrm{p}<0.001$ as highly significant.

\section{Results}

Impacted explants were cultivated with or without TNF- $\alpha$ for $24 \mathrm{~h}$ and processed for Live/dead-staining (Fig. 2A). Quantitative analysis revealed a significant reduction of vital cells from 59 to $31 \%$ after trauma but no further enhancement of trauma-induced cell death by TNF- $\alpha$. TNF- $\alpha$ stimulation of unimpacted explants did not reduce cell viability.

Quantitative analysis of the prostaglandin synthesis pathway revealed significant effects of trauma with TNF- $\alpha$ stimulation as shown in Fig. 3. PGE2 release was significantly increased by trauma with/without TNF- $\alpha$ whereas TNF- $\alpha$ alone caused no elevation (Fig. 3A). PGE2 synthesis only partly correlated to the gene expression of the corresponding enzymes at $24 \mathrm{~h}$. We observed a significantly enhanced gene expression of COX2 in TNF- $\alpha$-stimulated cartilage with/without impact. Trauma alone had a tendency to elevate COX2 mRNA level (Fig. 3C). PTGES tended to be slightly increased in trauma with/without TNF- $\alpha$ (Fig. 3D). The production of PGD2 was elevated significantly by trauma without and in trend by trauma with TNF- $\alpha$ in correlation with the gene expression of PTGDS (Fig. 3B and $\mathrm{E}$ ). The effects of impact with/without TNF- $\alpha$ on the NO 

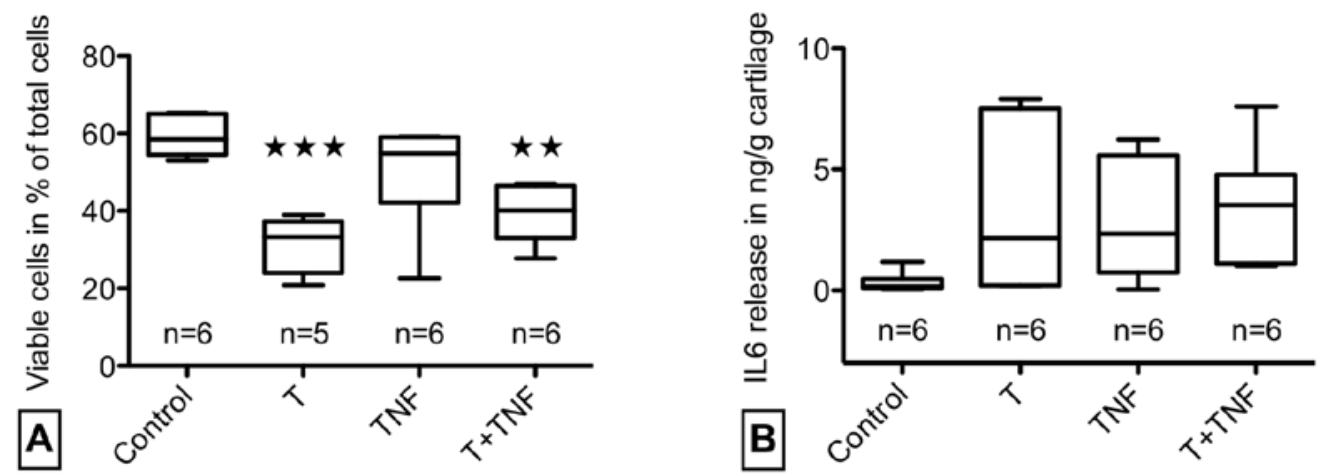

Figure 2. Chondrocyte viability and release of IL-6 in response to trauma and TNF- $\alpha$ stimulation. Cartilage explants were traumatized ( $0.59 \mathrm{~J})$, stimulated with TNF- $\alpha(100 \mathrm{ng} / \mathrm{ml})$ or traumatized + stimulated with TNF- $\alpha$. Cartilage explants without treatments served as control. (A) Cell viability after $24 \mathrm{~h}$. (B) IL-6 release after $24 \mathrm{~h}$. The values are shown as box plots, where each box represents the interquartile range. The line inside the box displays the median. The whiskers show the minimum and maximum values. ${ }^{* *} \mathrm{p}<0.01,{ }^{* * *} \mathrm{p}<0.001$. T, trauma; TNF, TNF- $\alpha$.
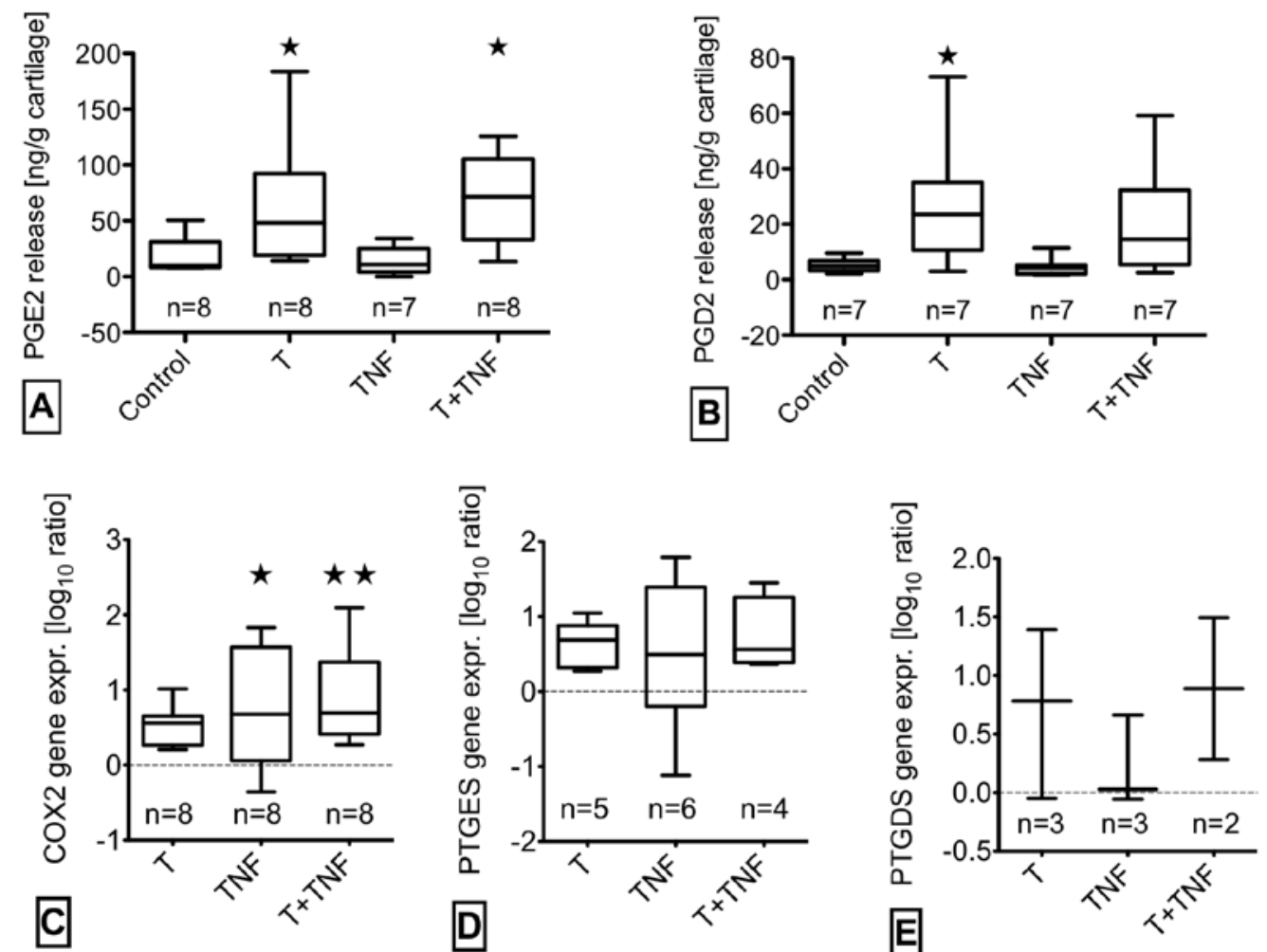

Figure 3. Effects of trauma and TNF- $\alpha$ stimulation on the prostaglandin synthesis pathway. Cartilage explants were traumatized $(0.59 \mathrm{~J})$, stimulated with TNF- $\alpha$ $(100 \mathrm{ng} / \mathrm{ml})$ or traumatized + stimulated with TNF- $\alpha$. Cartilage explants without treatments served as control. (A and B) Release of PGE2 and PGD2 after $24 \mathrm{~h}$. mRNA-expression of (C) COX2, (D) PTGES and (E) PTGDS after $24 \mathrm{~h}$ was determined by real-time PCR, expression levels are normalized to 18Sr RNA and shown relative to control. The values are shown as box plots, where each box represents the interquartile range. The line inside the box displays the median. The whiskers show the minimum and maximum values. ${ }^{*} \mathrm{p}<0.05,{ }^{* *} \mathrm{p}<0.01 . \mathrm{T}$, trauma; TNF, TNF- $\alpha$.

synthesis pathway are shown in Fig. 4 and revealed a significantly enhanced NOS2A gene expression and nitrite release by TNF- $\alpha$ stimulation. Though trauma with TNF- $\alpha$ tended to increase NOS2A gene expression 30 -fold by mean, NO release was hardly elevated. Using enzyme-linked immunosorbent assay, we determined the release of IL-6 after trauma and/or TNF- $\alpha$ stimulation by the cartilage explants. Fig. 2B shows an elevation of IL- 6 release in impacted and/or TNF- $\alpha$ stimulated explants. A parallel analysis of IL-1 $\beta$ and TNF- $\alpha$ release showed no activating effect of trauma and TNF- $\alpha$ stimulation caused no increased IL-1 $\beta$ production $(\mathrm{n}=9$ for control and trauma specimens, $\mathrm{n}=3$ for TNF- $\alpha$ and TNF- $\alpha+$ trauma specimens, data not shown).

While trauma increased osteoprotegerin release in half of the cases, concomitant TNF- $\alpha$ stimulation caused a consistent but not significant elevation. RANKL levels were significantly reduced by trauma with and without TNF- $\alpha$. TNF- $\alpha$ stimulation alone had no influence on OPG/RANKL release (Fig. 5A and B). 

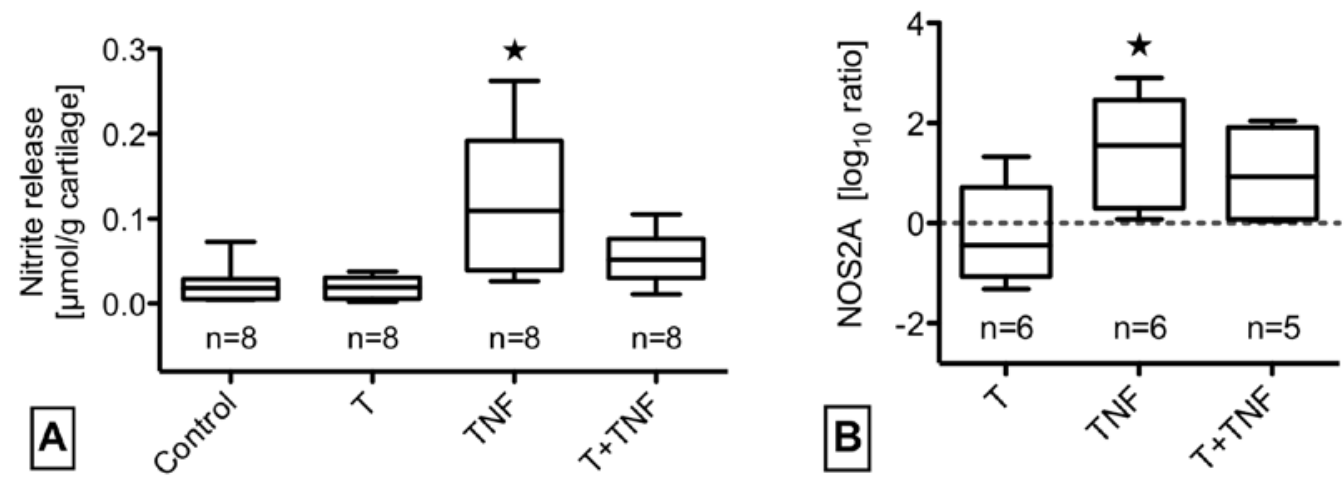

Figure 4. Effects of trauma and TNF- $\alpha$ stimulation on NO synthesis pathway. Cartilage explants were traumatized (0.59 J), stimulated with TNF- $\alpha$ (100 ng/ml) or traumatized + stimulated with TNF- $\alpha$. Cartilage explants without treatments served as control. (A) Release of nitrite after 24 h. (B) mRNA-expression of NOS2A after $24 \mathrm{~h}$ was determined by real-time PCR, expression levels are normalized to 18Sr RNA and shown relative to control. The values are shown as box plots, where each box represents the interquartile range. The line inside the box displays the median. The whiskers show the minimum and maximum values. ${ }^{*}<<0.05$. T, trauma; TNF, TNF- $\alpha$.
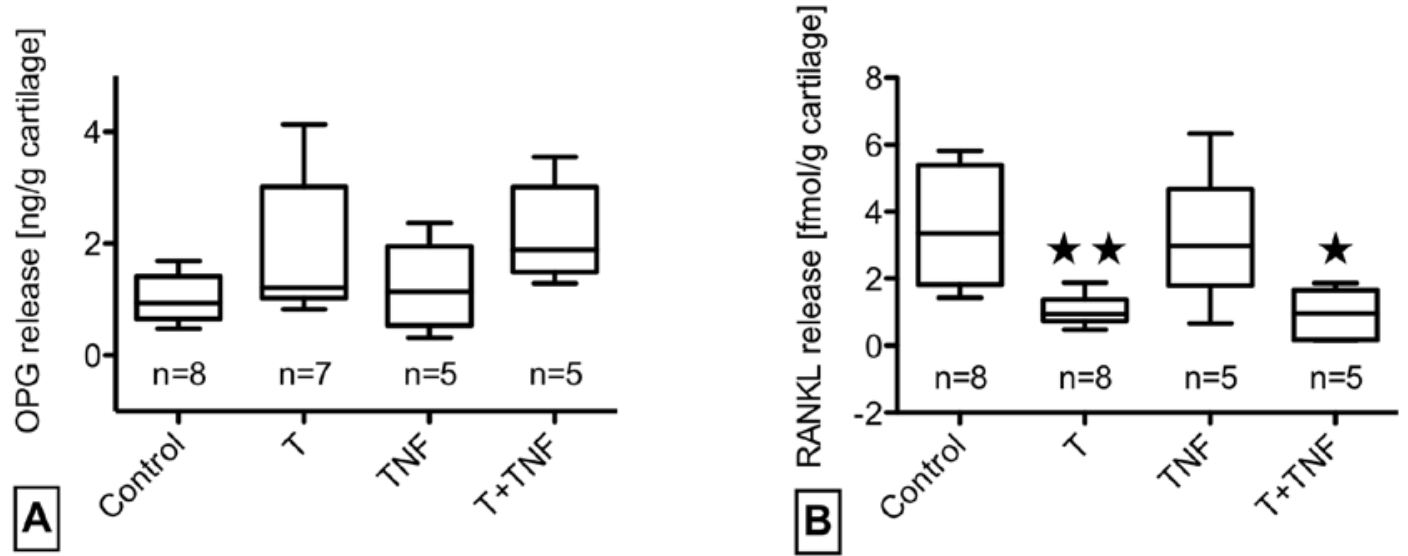

Figure 5. Effects of trauma and TNF- $\alpha$ stimulation on release of OPG/RANKL. Cartilage explants were traumatized $(0.59 \mathrm{~J})$, stimulated with TNF- $\alpha 100 \mathrm{~g} / \mathrm{ml}$ or traumatized + stimulated with TNF- $\alpha$. Cartilage explants without treatments served as control. (A and B) Release of OPG and RANKL after $24 \mathrm{~h}$. The values are shown as box plots, where each box represents the interquartile range. The line inside the box displays the median. The whiskers show the minimum and maximum values. ${ }^{*} \mathrm{p}<0.05,{ }^{* *} \mathrm{p}<0.01$. T, trauma; TNF, TNF- $\alpha$.

Table I. Effects of trauma and TNF- $\alpha$ stimulation on gene expression of different degrading enzymes and matrix components.

\begin{tabular}{|c|c|c|c|c|c|c|}
\hline & & Gene & ssion $\left(\log _{10} \mathrm{ra}\right.$ & lative to contr & & \\
\hline & MMP1 & MMP3 & ADAMTS4 & ADAMTS5 & COL2A1 & ACAN \\
\hline $\mathrm{T}$ & 0.2 & 0.2 & 0.3 & 0.2 & -0.5 & -0.4 \\
\hline & $(-0.7$ to 1.5$)$ & $(-0.2$ to 0.8$)$ & $(-0.5$ to 0.3$)$ & $(-0.4$ to 1.4$)$ & $(-0.8$ to 0.2$)$ & $(-0.5$ to -0.2$)$ \\
\hline $\mathrm{TNF}$ & $0.7^{\mathrm{a}}$ & 0.3 & -0.4 & -0.3 & -0.2 & -0.1 \\
\hline & (0.7 to 1.6$)$ & $(0.1$ to 0.5$)$ & $(-0.9$ to 0.1$)$ & $(-0.5$ to 0.2$)$ & $(-0.5$ to 0.1$)$ & $(-0.6$ to 0.4$)$ \\
\hline $\mathrm{T}+\mathrm{TNF}$ & $0.8^{\mathrm{a}}$ & 0.3 & 0.1 & -0.1 & $-0.6^{\mathrm{a}}$ & -0.5 \\
\hline & $(-0.2$ to 1.9$)$ & $(-0.2$ to 1.0$)$ & $(-0.1$ to 0.4$)$ & $(-1.0$ to 0.5$)$ & $(-1.1$ to -0.1$)$ & $(-1.2$ to 0.3$)$ \\
\hline
\end{tabular}

Cartilage explants were traumatized $(0.59 \mathrm{~J})$, stimulated with TNF- $\alpha(100 \mathrm{ng} / \mathrm{ml})$ or traumatized + stimulated with TNF- $\alpha$. Cartilage explants without treatments served as control. mRNA-expression of MMP1 $(n=8)$, MMP3 $(n=4)$, ADAMTS4 ( $\geq 3$ ), ADAMTS5 ( $=4)$, COL2A1 $(n=4)$ and ACAN $(n=4)$ after $24 \mathrm{~h}$ was determined by real-time PCR, expression levels are normalized to $18 \mathrm{Sr}$ RNA and are shown as log 10 ratio relative to control. The values are shown as mean (with min and max values beneath). ${ }^{\mathrm{a}} \mathrm{p}<0.05$. $\mathrm{T}$, trauma; TNF, TNF- $\alpha$. 
Table I shows trauma and TNF- $\alpha$ effects on gene expression of different degrading enzymes and matrix components. TNF- $\alpha$ with/without trauma significantly induced MMP1 gene expression. The combined treatment resulted in a significantly reduced COL2A1 gene expression and a trend for lower aggrecan gene expression. The effect on the expression of these major matrix components of cartilage could be mainly attributed to the mechanical trauma.

\section{Discussion}

In synovial joints trauma-induced release of proinflammatory mediators like TNF- $\alpha$ drive the pathogenetic process of cartilage degeneration as TNF- $\alpha$ potentiates trauma-induced loss of proteoglycans (18). We therefore asked for further synergistic effects and investigated the single and combined effect of a defined blunt cartilage trauma and TNF- $\alpha$ exposure on chondrocyte viability, prostaglandin, nitric oxide, IL-6 and OPG/ RANKL metabolism as well as gene expression of catabolic and anabolic genes in human early-stage osteoarthritic cartilage explants. The focus on the first $24 \mathrm{~h}$ after trauma disregards possible effects occurring at later time points but previous studies identified this time frame as determining for cell survival after cartilage trauma (19) and sufficient to assess possible apoptotic effects of TNF- $\alpha$ in chondrocytes $(21,26)$.

Twenty-four hours after trauma, a significant reduction of viable cells to about $50 \%$ of untreated samples was observed, which is comparable to other human cartilage trauma models $(27,28)$. As trauma did not induce intrinsic TNF- $\alpha$ release in our in vitro model, the cytokine was only present after exogenous application and cannot be responsible for the primary traumainduced cell death. Even additional stimulation with exogenous TNF- $\alpha$ at a concentration known to induce apoptosis under permissive conditions (26) did not enhance trauma-induced cell death in tissue culture after $24 \mathrm{~h}$. Indeed, TNF- $\alpha$ has previously been reported not to be proapoptotic in chondrocytes unless they were specifically sensitized for apoptosis $(20,21,26)$. Possibly, the embedding in the extracellular matrix may be an essential survival factor for chondrocytes in tissue culture preventing TNF- $\alpha$-induced DNA cleavage (29). As shown here a preceding single impact trauma known to damage the matrix mechanically and to cause apoptosis in human cartilage itself (7), did not induce sensitivity to TNF- $\alpha$-mediated apoptosis. One might speculate that the trauma-associated increase in OPG-expression -although not statistically significant- may have prevented a further increase in chondrocyte death by inhibition of TRAIL (TNF-related apoptosis inducing ligand)-mediated effects as previously described for myeloma cells (30) since TRAIL-mediated apoptosis has also been observed in chondrocytes (31). Anyhow, the results indicate that stress signaling, matrix deformation and its partial disruption induced by a single impact trauma does not promote early TNF- $\alpha$-mediated apoptosis in human cartilage.

PGE2 and PGD2 release and related gene expression was increased by trauma, confirming previous studies $(19,27)$. However, additional TNF- $\alpha$ stimulation did not enhance these trauma-induced effects. Nor did TNF- $\alpha$ stimulate PGE2 and PGD2 release after $24 \mathrm{~h}$ in unimpacted cartilage, although the mean COX2 gene expression was elevated at this time point. May be a late induction of gene expression by TNF- $\alpha$ is not yet reflected in an enhanced PGE2 or PGD2 synthesis after $24 \mathrm{~h}$. Another reason may arise from possible interactions between NO and PGE2, since TNF- $\alpha$ lead to highly induced NO levels. Among versatile effects, NO is described to inhibit PGE2 synthesis $(32,33)$. NO release could not be induced by trauma, but was increased by additional TNF- $\alpha$. Compared to stimulation of unimpacted cartilage, however, TNF- $\alpha$ induced NOS2A-expression and NO release was mitigated in case of a preceeding trauma. This mitigation, again, could be a sign of interactions between NO and PGE2 metabolism, since trauma induced high levels of PGE2 (34).

We could show a significant decrease in RANKL and a trend for an increase in OPG release after trauma. TNF- $\alpha$ could not enhance this effect. Expression of OPG and RANKL in human cartilage and chondrocytes has been previously described $(25,35)$. The increased OPG release after trauma with or without TNF- $\alpha$ could be a consequence of the increase in PGE2 (36). The decrease of RANKL after trauma with or without TNF- $\alpha$ indicates the involvement of another regulatory mechanism related to the mechanical impact. In fibrochondrocytes of the meniscus it could be shown that cyclic tensile strain downregulates the expression of RANKL in response to IL-1 $\beta$ (37). In human osteoblasts, however, intermittent cyclic tensile strength increased RANKL expression while OPG-expression was not affected (38). This indicates a cell-type specific response or interference of pro-inflammatory stimuli within the mesenchymal lineage. In the pathophysiologic context of a blunt cartilage trauma an increase of OPG and a parallel decrease of RANKL release could possibly contribute to the development of subchondral sclerosis.

In agreement with previous reports on synergistic effects of cartilage trauma and $\mathrm{TNF}-\alpha$ with respect to proteoglycan loss $(17,18)$, we found an early increase of MMP1 gene expression after traumatization with TNF- $\alpha$ exposure. MMP1 may contribute to proteoglycan loss by degradation of the collagenous network, link protein and aggrecan (39). The reduction of COL2A1 gene expression by trauma and TNF- $\alpha$ may additionally support the overall matrix-catabolic effect. The expression of ADAMTS4 and ADAMTS5 was not affected $24 \mathrm{~h}$ after treatment. An induction of these aggrecanases probably occurs somewhat later since respective aggrecan cleavage products have been identified in synovial fluid in the first two weeks after trauma (40). IL-6, which was induced by trauma and/or TNF- $\alpha$ stimulation in our study, has previously been shown to enhance proteoglycan loss induced by trauma and TNF- $\alpha$ (18).

The use of well preserved human cartilage from patients with osteoarthritis in the present study may have influenced the results because of effects on the basal expression levels of the genes or mediators studied. The susceptibility of osteoarthritic chondrocytes to TNF- $\alpha$ should not be diminished, as a higher number of the p55 TNF- $\alpha$ receptor is expressed in OA cartilage (14). The advanced age of the donors means no limitation for this study as the risk for the development of posttraumatic osteoarthritis even increases with patient age (41). Furthermore, the individual responsiveness to proinflammatory stimuli might vary considerably due to genetical divergence as observed in the context of osteoarthritis or rheumatoid arthritis $(42,43)$. This fact may also partially explain the high interindividual variation observed. Nevertheless, the in vitro system used in this study represents a human model that allows to analyze cell-biologic 
effects of defined blunt cartilage injury in the native 3-dimensional tissue context. Since several well-known responses to a single impact trauma and to TNF- $\alpha$ stimulation are preserved it can be regarded as a useful alternative to similar experimental models with bovine tissue (17).

In conclusion, we found that exposure of traumatized human cartilage to TNF- $\alpha$ does not lead to increased chondrocyte death within the first $24 \mathrm{~h}$. PGE2, PGD2 and IL-6 synthesis was not markedly modulated by TNF- $\alpha$ while TNF- $\alpha$-induced NO release was reduced in case of trauma. In agreement with previous results the expression of MMP1 was enhanced (15) but expression of ADAMTS4 and ADAMTS5 was not affected in the early post-traumatic phase. These results indicate that in the initial phase after blunt cartilage injury, TNF- $\alpha$ does not potentiate cell death and the release of inflammatory mediators while degradative processes are rapidly enhanced (18). Therefore, TNF- $\alpha$ inhibitors such as etanercept, infliximab or adalimumab, recently suggested for treatment of joint injuries (5) could be complemented by therapeutics that mitigate cell death-like antioxidants in order to limit subsequent cartilage damage $(44,45)$. A more detailed knowledge on the complex interactive mechanisms and signaling pathways in the initial phase after cartilage trauma may finally lead to bi- or multidirectional pharmacotherapeutic approaches to ameliorate long-term consequences of joint injuries. One promising target in this context may be the MAPKs that are involved in cell survival, inflammation and degradative processes $(44,46,47)$.

\section{Acknowledgements}

We would like to thank Brunhilde Amann for excellent technical assistance. This study was supported by the German Research Council (DFG, grant KFO 200, BR 919/5-1).

\section{References}

1. Szczodry M, Coyle CH, Kramer SJ, Smolinski P and Chu CR Progressive chondrocyte death after impact injury indicates a need for chondroprotective therapy. Am J Sports Med 37: 2318-2322, 2009.

2. Majewski M, Habelt S and Steinbrück K: Epidemiology of athletic knee injuries: A 10-year study. Knee 13: 184-188, 2006.

3. Baker P, Reading I, Cooper C and Coggon D: Knee disorders in the general population and their relation to occupation. Occup Environ Med 60: 794-797, 2003.

4. Westin M, Alricsson M and Werner S: Injury profile of competitive alpine skiers: a five-year cohort study. Knee Surg Sports Traumatol Arthrosc 20: 1175-1181, 2012.

5. Lawrence JT, Birmingham J and Toth AP: Emerging ideas: prevention of posttraumatic arthritis through interleukin-1 and tumor necrosis factor-alpha inhibition. Clin Orthop Relat Res 469: 3522-3526, 2011.

6. Phillips DM and Haut RC: The use of a non-ionic surfactant (P188) to save chondrocytes from necrosis following impact loading of chondral explants. J Orthop Res 22: 1135-1142, 2004.

7. D'Lima DD, Hashimoto S, Chen PC, Colwell CW and Lotz MK: Human chondrocyte apoptosis in response to mechanical injury. Osteoarthritis Cartilage 9: 712-719, 2001.

8. DiMicco MA, Patwari P, Siparsky PN, et al: Mechanisms and kinetics of glycosaminoglycan release following in vitro cartilage injury. Arthritis Rheum 50: 840-848, 2004.

9. Aroen A, Loken S, Heir S, et al: Articular cartilage lesions in 993 consecutive knee arthroscopies. Am J Sports Med 32: 211-215, 2004.

10. Tang Z, Yang L, Wang Y, et al: Contributions of different intraarticular tissues to the acute phase elevation of synovial fluid MMP-2 following rat ACL rupture. J Orthop Res 27: 243-248, 2009.
11. Irie $\mathrm{K}$, Uchiyama $\mathrm{E}$ and Iwaso $\mathrm{H}$ : Intraarticular inflammatory cytokines in acute anterior cruciate ligament injured knee. Knee 10: 93-96, 2003.

12. Goldring MB and Marcu KB: Cartilage homeostasis in health and rheumatic diseases. Arthritis Res Ther 11: 224, 2009.

13. De Ceuninck F, Dassencourt L and Anract P: The inflammatory side of human chondrocytes unveiled by antibody microarrays. Biochem Biophys Res Commun 323: 960-969, 2004.

14. Fernandes JC, Martel-Pelletier J and Pelletier JP: The role of cytokines in osteoarthritis pathophysiology. Biorheology 39: 237-246, 2002.

15. Stevens AL, Wishnok JS, White FM, Grodzinsky AJ and Tannenbaum SR: Mechanical injury and cytokines cause loss of cartilage integrity and upregulate proteins associated with catabolism, immunity, inflammation, and repair. Mol Cell Proteomics 8: 1475-1489, 2009.

16. Demircan K, Hirohata S, Nishida K, et al: ADAMTS-9 is synergistically induced by interleukin-1beta and tumor necrosis factor alpha in OUMS-27 chondrosarcoma cells and in human chondrocytes. Arthritis Rheum 52: 1451-1460, 2005.

17. Patwari P, Cook MN, DiMicco MA, et al: Proteoglycan degradation after injurious compression of bovine and human articular cartilage in vitro: interaction with exogenous cytokines. Arthritis Rheum 48: 1292-1301, 2003.

18. Sui Y, Lee JH, DiMicco MA, et al: Mechanical injury potentiates proteoglycan catabolism induced by interleukin- 6 with soluble interleukin-6 receptor and tumor necrosis factor alpha in immature bovine and adult human articular cartilage. Arthritis Rheum 60: 2985-2996, 2009

19. Joos H, Hogrefe C, Rieger L, Durselen L, Ignatius A and Brenner RE: Single impact trauma in human early-stage osteoarthritic cartilage: Implication of prostaglandin D2 but no additive effect of IL-1beta on cell survival. Int J Mol Med 28: 271-277, 2011.

20. Kim H and Song WS: TNF-alpha-mediated apoptosis in chondrocytes sensitized by MG132 or actinomycin D. Biochem Biophys Res Commun 295: 937-944, 2002.

21. López-Armada MJ, Caramés B, Lires-Deán M, et al: Cytokines, tumor necrosis factor-alpha and interleukin-1beta, differentially regulate apoptosis in osteoarthritis cultured human chondrocytes. Osteoarthritis Cartilage 14: 660-669, 2006.

22. Goldring MB and Goldring SR: Osteoarthritis. J Cell Physiol 213: 626-634, 2007.

23. Umlauf D, Frank S, Pap T and Bertrand J: Cartilage biology, pathology, and repair. Cell Mol Life Sci 67: 4197-4211, 2010.

24. Kearns AE, Khosla S and Kostenuik PJ: Receptor activator of nuclear factor kappaB ligand and osteoprotegerin regulation of bone remodeling in health and disease. Endocr Rev 29: 155-192, 2008.

25. Komuro H, Olee T, Kühn K, et al: The osteoprotegerin/receptor activator of nuclear factor kappaB/receptor activator of nuclear factor kappaB ligand system in cartilage. Arthritis Rheum 44: 2768-2776, 2001.

26. Yoshimura F, Kanno H, Uzuki M, Tajima K, Shimamura T and Sawai T: Downregulation of inhibitor of apoptosis proteins in apoptotic human chondrocytes treated with tumor necrosis factor-alpha and actinomycin D. Osteoarthritis Cartilage 14: 435-441, 2006

27. Jeffrey JE and Aspden RM: Cyclooxygenase inhibition lowers prostaglandin E2 release from articular cartilage and reduces apoptosis but not proteoglycan degradation following an impact load in vitro. Arthritis Res Ther 9: R129, 2007.

28. D'Lima DD, Hashimoto S, Chen PC, Colwell CW and Lotz MK: Impact of mechanical trauma on matrix and cells. Clin Orthop Relat Res (Suppl 391): S90-S99, 2001.

29. Fischer BA, Mundle S and Cole AA: Tumor necrosis factor-alpha induced DNA cleavage in human articular chondrocytes may involve multiple endonucleolytic activities during apoptosis. Microsc Res Tech 50: 236-242, 2000.

30. Shipman CM and Croucher PI: Osteoprotegerin is a soluble decoy receptor for tumor necrosis factor-related apoptosis-inducing ligand/Apo2 ligand and can function as a paracrine survival factor for human myeloma cells. Cancer Res 63: 912-916, 2003.

31. Pettersen I, Figenschau Y, Olsen E, Bakkelund W, Smedsrod B and Sveinbjornsson B: Tumor necrosis factor-related apoptosisinducing ligand induces apoptosis in human articular chondrocytes in vitro. Biochem Biophys Res Commun 296: 671-676, 2002.

32. Amin AR, Attur M and Abramson SB: Nitric oxide synthase and cyclooxygenases: distribution, regulation, and intervention in arthritis. Curr Opin Rheumatol 11: 202-209, 1999. 
33. Guilak F, Fermor B, Keefe FJ, et al: The role of biomechanics and inflammation in cartilage injury and repair. Clin Orthop Relat Res 423: 17-26, 2004.

34. Marotta P, Sautebin L and Di Rosa M: Modulation of the induction of nitric oxide synthase by eicosanoids in the murine macrophage cell line J774. Br J Pharmacol 107: 640-641, 1992.

35. Kwan Tat S, Amiable N, Pelletier JP, et al: Modulation of OPG, RANK and RANKL by human chondrocytes and their implication during osteoarthritis. Rheumatology (Oxford) 48: 1482-1490, 2009.

36. Moreno-Rubio J, Herrero-Beaumont G, Tardio L, AlvarezSoria MA and Largo R: Nonsteroidal antiinflammatory drugs and prostaglandin $\mathrm{E}(2)$ modulate the synthesis of osteoprotegerin and RANKL in the cartilage of patients with severe knee osteoarthritis. Arthritis Rheum 62: 478-488, 2010.

37. Deschner J, Wypasek E, Ferretti M, Rath B, Anghelina M and Agarwal S: Regulation of RANKL by biomechanical loading in fibrochondrocytes of meniscus. J Biomech 39: 1796-1803, 2006.

38. Kreja L, Liedert A, Hasni S, Claes L and Ignatius A: Mechanical regulation of osteoclastic genes in human osteoblasts. Biochem Biophys Res Commun 368: 582-587, 2008.

39. Sternlicht MD and Werb Z: How matrix metalloproteinases regulate cell behavior. Annu Rev Cell Dev Biol 17: 463-516, 2001.

40. Struglics A, Hansson M and Lohmander LS: Human aggrecanase generated synovial fluid fragment levels are elevated directly after knee injuries due to proteolysis both in the inter globular and chondroitin sulfate domains. Osteoarthritis Cartilage 19: 1047-1057, 2011.
41. Roos H, Adalberth T, Dahlberg L and Lohmander LS: Osteoarthritis of the knee after injury to the anterior cruciate ligament or meniscus: the influence of time and age. Osteoarthritis Cartilage 3: 261-267, 1995.

42. Schneider EM, Du W, Fiedler J, et al: The (-765 G->C) promoter variant of the COX-2/PTGS2 gene is associated with a lower risk for end-stage hip and knee osteoarthritis. Ann Rheum Dis 70: 1458-1460, 2010.

43. Van der Pouw Kraan TC, van Gaalen FA, Kasperkovitz PV, et al: Rheumatoid arthritis is a heterogeneous disease: evidence for differences in the activation of the STAT-1 pathway between rheumatoid tissues. Arthritis Rheum 48: 2132-2145, 2003.

44. Ding L, Heying E, Nicholson N, et al: Mechanical impact induces cartilage degradation via mitogen activated protein kinases. Osteoarthritis Cartilage 18: 1509-1517, 2010.

45. Goodwin W, McCabe D, Sauter E, et al: Rotenone prevents impactinduced chondrocyte death. J Orthop Res 28: 1057-1063, 2010.

46. Takebe K, Nishiyama T, Hayashi S, et al: Regulation of p38 MAPK phosphorylation inhibits chondrocyte apoptosis in response to heat stress or mechanical stress. Int J Mol Med 27 329-335, 2011.

47. Radons J, Bosserhoff AK, Graessel S, Falk W and Schubert TEO: p38MAPK mediates IL-1-induced down-regulation of aggrecan gene expression in human chondrocytes. Int J Mol Med 17: 661-668, 2006. 